\title{
Augmentation Rhinoplasty with Expanded Polytetrafluoroethylene: A Ten-Year Experience for Safety
}

\author{
Dongmin Shin, Sihyung Kang, and Yong Gi Jung (iD \\ Department of Otolaryngology, Samsung Changwon Hospital, Sungkyunkwan University School of Medicine, Changwon, Korea
}

\section{Expanded Polytetrafluoroethylene을 이용한 융비술: 재료의 안전성에 대한 10 년의 경험}

신동민 · 강시형 · 정용기

성균관대학교 의과대학 삼성창원병원 이비인후과학교실

Received May 6, 2019

Revised July 9,2019

Accepted July 11, 2019

Address for correspondence

Yong Gi Jung, MD, PhD

Department of Otorhinolaryngology-

Head and Neck Surgery,

Samsung Changwon Hospital,

Sungkyunkwan University

School of Medicine,

158 Paryong-ro, Masanhoewon-gu,

Changwon 51353, Korea

Tel +82-55-233-5982

Fax $+82-55-233-5441$

E-mail ent.jyg@gmail.com

Background and Objectives Expanded polytetrafluoroethylene (ePTFE) is an alloplastic implant widely used in augmentation rhinoplasty. However, ePTFE implant is known to be vulnerable to postoperative infection and inflammation. We aimed to verify the safety of the material by analyzing the results of augmentation rhinoplasty using ePTFE carried out in a single institution for 10 years.

Subjects and Method From April 2009 to June 2018, 238 patients who underwent augmentation rhinoplasty with ePTFE were included in the study. There were 187 male patients and 51 female patients. Patients' medical records, preoperative and postoperative photographs were analyzed, and postoperative implant migration, inflammation, and infection were investigated. Results Of the 238 patients, 10 underwent revision surgery, and 87 (36.6\%) underwent concomitant osteotomy for the correction of the deviated nose. Of the 5 patients $(2.1 \%)$ who showed postoperative implant migration, 4 patients belonged to the osteotomy patients group while 1 patient belonged to the no-osteotomy group. There was more frequent implant migration in patients who underwent osteotomy; however, there was no statistically significant difference $(p=0.06)$. In all of the five patients, the degree of implant migration was minimal, therefore no patient required revision surgery. No inflammatory reaction or infection was found after surgery.

Conclusion ePTFE is a safe material for augmentation rhinoplasty and is not susceptible to infection after surgery if used through appropriate surgical procedures.

Korean J Otorhinolaryngol-Head Neck Surg 2019;62(12):706-11

Key Words Infection · Inflammation · Osteotomy · Polytetrafluoroethylene - Rhinoplasty.

\section{서 론}

2000년대 이후 외모에 대한 관심이 급격하게 증가하면서 외비 성형술은 국내에서 가장 많이 시행되는 미용 수술이 되

This is an Open Access article distributed under the terms of the Creative Common Attribution Non-Commercial License (https://creativecommons.org/licenses/by-nc/4.0) which permits unrestricted non-commercial use, distribution, and reproduction in any medium, provided the original work is properly cited.
었으며 국내 외비 성형 분야는 질적 및 양적으로 큰 성장을 하고 있다.1) 특히 낮은 코를 높이기 위한 융비술(augmentation rhinoplasty)은 동양인의 외비 성형술에서 가장 중요한 부분 으로 여겨지고 있다. ${ }^{2)}$ 융비술을 위한 이식물로 자가(autologous) 재료, 동종(homologous) 재료 및 실리콘이나 expanded polytetrafluoroethylene (ePTFE)와 같은 인공(alloplastic) 이식물 등 여러 재료가 사용되고 있지만 각 재료가 가지 
고 있는 장단점이 명확하기 때문에 재료의 선택은 집도의의 선택에 달려 있다. 여러 재료 중 자가 재료가 가장 바람직하다 는 보고가 많으나, 동양인의 경우 융비술을 위해 많은 양의 재료가 필요하기 때문에 비중격 연골이나 귀 연골만으로는 충분한 양을 얻기 어렵다. ${ }^{3)}$ 많은 양의 연골이 필요한 경우 자 가 늑연골을 채취하여 사용할 수 있지만, 이식 재료의 뒤틀림 변형(warping)이나 공여 부위 반흔 등 합병증이 발생할 수 있다.

$\mathrm{ePTFE}$ 는 실리콘과 함께 융비술에서 가장 많이 사용되는 인공 이식물이다. ${ }^{5)} \mathrm{ePTFE}$ 는 높은 생체 적합성을 가지고 있 어 각종 혈관 이식물 및 인체의 막성 구조를 대체하기 위한 재료로 사용되어 왔으며, 30여 년 전부터 융비술의 재료로도 쓰이고 있다.) $\mathrm{ePTFE}$ 는 실리콘과 비교하여 보다 자연스러운 코 모양을 만들 수 있고, 재료의 제단 및 조작이 쉬워 국내외 에서 널리 사용되고 있다. ${ }^{3,7)}$

그러나 ePTFE는 자가 연골 또는 실리콘 등에 비해 염증에 취약하다는 인식이 많으며 ePTFE를 이용한 융비술 시행 후 염증이 발생하였을 때, 염증의 원인이 $\mathrm{ePTFE}$ 라고 판단하는 경우가 많다. 그러나 2008년 수술 후 감염 등의 문제로 이식 물을 제거한 비율을 조사한 메타 분석 논문에서 ePTFE의 수술 후 제거율은 $3.1 \%$ 였던 반면, 실리콘 이식물의 경우 $6.5 \%$ 로 더 높았다고 보고하였다. ${ }^{8)}$ 그러나 수술 후 감염은 이식물 자체에 의해 영향을 받을 수도 있지만, 수술을 시행하는 환경 및 환자의 상태, 함께 시행하는 술기의 종류에 따라 달라질 수 있어서 기존의 연구 결과를 그대로 받아들이기 어렵다. 또 한 이전의 연구에서 주로 사용된 $\mathrm{ePTFE}$ 이식물은 코 성형으 로 승인받은 재료가 아니라 연조직 패치로 개발된 재료를 코 에 사용하였으며, 최근 사용되고 있는 코 이식재로 승인받은 $\mathrm{ePTFE}$ 와 조직의 미세 구조 및 물리적 성질이 달라 이전 재 료를 이용한 연구 결과가 새로운 $\mathrm{ePTFE}$ 의 사용 결과를 대변 한다고 보기 어렵다. ${ }^{7,9)}$

저자들은 코 성형 재료로 승인을 받은 ePTFE를 이용한 비 배부 융비술에 대한 10 년간의 수술 결과를 분석하여 위 재료 의 안전성에 대해 알아보고자 하였다.

\section{대상 및 방법}

\section{연구 설계와 대상 환자}

2009년 4월 2018년 6월까지 성균관대학교 삼성창원병원에 서 외비 성형술을 받은 환자 중 융비술 이식물로 $\mathrm{ePTFE}$ 를 사용하였던 환자의 의무기록을 후향적으로 분석하였고, 환자 의 수술 전 후 사진을 비교하여 수술 결과에 대해 평가하였 다. 본 연구는 해당 기관 임상연구심의위원회의 승인(IRB No.
2018-SCMC-043-02)하에 후향적 연구로 이루어졌다. 연구 에 포함된 모든 환자의 수술 및 수술 후 치료는 1 인의 숙련된 술자(YG Jung)에 의해 시행되었으며 수술 전 처치, 수술 후 투약 및 외래 추적 관찰은 모든 환자에서 동일하였다.

연구에 포함된 환자의 나이, 성별, 재수술 여부, 사용된 $\mathrm{ePT}-$ $\mathrm{FE}$ 이식물 높이, 절골술(osteotomy) 동반 여부, 수술 후 감염 등의 염증 반응, 수술 후 이식물 이동, 이식물 노출 등에 대해 조사하였다.

\section{수술 방법}

환자의 눈을 보호한 후 이마를 포함한 안면부, 경부, 양측 이개 부위까지 $10 \%$ 베타딘 용액을 이용하여 소독하고 살균 효과를 위해 베타딘 용액이 마를 때까지 기다렸다. 환자의 모 발을 항균 효과가 있는 $\operatorname{Ioban}^{\mathrm{TM}}$ (3M, Maplewood, MN, USA) 수술 드렙을 이용하여 수술 부위로부터 완전하게 분리하였 고, 입술을 포함한 구강 부위와 기관삽관 튜브도 마찬가지로 덮어 분리하여 철저한 무균 수술 부위가 되도록 준비하였다. 연구에 포함된 238예 모두 전신마취를 시행하고 경비주 절개 술을 통한 비외 접근법을 통해 수술을 하였다. 비배부의 골막 에 날카로운 거상기를 이용하여 절개를 가하고 골막 하부로 접근하여 이식물을 위한 공간을 확보하였고, 이식물 삽입 전 $50 \mathrm{cc}$ 주사기에 18 게이지 바늘을 연결하여 강한 압력으로 비 배부 세척을 시행하여 수술 부위에 남아 있는 혈괴 및 수술 중 오염되었을 가능성이 있는 분비물 등을 제거하였다. 이렇 게 할 경우 12 pounds per square inch(PSI) 정도의 압력을 조직 표면에 전달할 수 있으며, 표면에 존재할 수 있는 감염원 을 효과적으로 제거할 수 있다(Fig. 1). ${ }^{10)}$ 비배부 공간에 대한

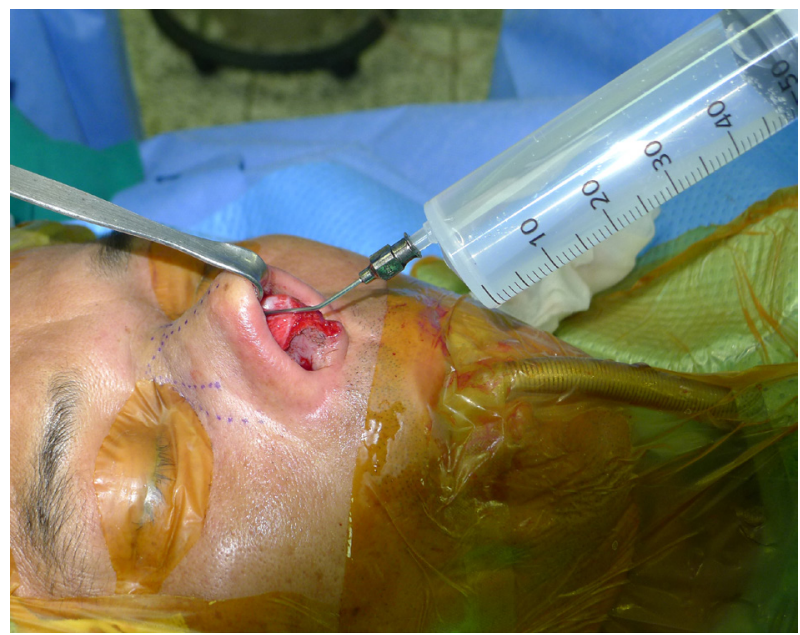

Fig. 1. It is necessary to perform frequent high-pressure irrigation in the surgical field. The blood clots and debris accumulated at the surgical field may become the nidus of postoperative inflammation and infection. Irrigation with a $50 \mathrm{cc}$ syringe equipped with 18 gauge needle is sufficient to remove contaminants from the surgical field. 
세척을 시행하여 깨끗하게 한 뒤 이식물을 삽입하기 전 비강 내에서 사용하였던 흡인기 및 거상기 등의 기구는 이식물이 삽입 될 비배부 공간에서 사용하지 않도록 하여 비강 내에서 비배부 공간으로 감염원이 이동할 수 있는 가능성을 차단하 였다. 모든 환자에서 사용된 ePTFE는 Surgiform $2 \mathrm{~mm}$ SFAM sheet(Surgiform Technology, Lugoff, SC, USA)였으 며 비배부 삽입 직전 포장을 개방하여 공기 중 노출을 최소 화하였다. 모든 환자에게 새 이식물을 사용하였고, 사용 중 남은 ePTFE 이식물은 모두 폐기하였다. ePTFE 포장 개봉 전 집도의, 수술 보조자는 모두 새 수술 장갑으로 교체하여 장갑에 붙어 있는 분비물 및 혈괴가 이식물에 붙지 않도록 하 였다. 이식물을 조작하고 제단하기 위한 수술 기구는 별도의 트레이를 이용하여 소독을 시행하여 수술 중 외부에 노출되 지 않도록 보관하였으며, 이식물 개봉 직후 트레이를 열어 깨 끗한 기구를 이용하여 $\mathrm{ePTFE}$ 조작하였다. 환자의 비배부 높 이에 따라 이식물을 디자인하였고 $2 \mathrm{~mm}$ 보다 두꺼운 두께의 이식물이 필요한 경우 $2 \mathrm{~mm}$ ePTFE를 겹친 후 5-0 PDS (Ethicon, Bridgewater, OH, USA)를 이용하여 1 2회 봉합 하였다. 필요에 따라 이식물 전장을 여러 겹으로 만들기도 하 였으며, 비첨 상부 또는 미간 사이 등 부분적으로 두꺼운 이 식물이 필요한 경우 필요한 부분만 여러 겹 겹쳐 사용하였다 (Fig. 2). 이식물 조작 중 발생할 수 있는 오염을 줄이기 위해 완성된 이식물을 베타딘 용액에 5 분간 담근 후 사용 직전 생 리 식염수로 세척하여 남아 있는 베타딘 용액을 모두 제거한 한 뒤 비배부에 삽입하였다. 연구에 포함된 모든 환자에서 위 와 같은 동일한 과정을 통해 이식물을 조작하였다.

수술 종료 후 양측 비강에 silastic sheet를 삽입하고 양측 비강에 항생제 연고를 도포한 거즈를 충전한 뒤 술 후 비배부 고정을 위해 Denver nasal splint(Summit medical, St. Paul, $\mathrm{MN}, \mathrm{USA}$ )를 거치하여 1 주간 유지하였고 같은 기간 광범위
경구 항생제를 투여하였다.

이식물의 이동에 대한 평가는 수술에 참여하지 않은 의료 인 2인이 각각 수술 전 사진과 수술 직후 사진, 그리고 수술 후 추적 관찰 기간 중의 사진을 분석하여 이식물이 이동하였 다고 1 명이라도 평가한 경우, 그리고 해당 환자가 이식물이 이 동하였다고 진술한 경우 이동으로 간주하였다. 염증 및 감염, 이식물의 이동, 그리고 절골술 동반 시행 여부와의 관계는 Fisher's exact 검정을 통해 분석하였고 통계 분석에는 SPSS Ver. 18.0(SPSS Inc, Chicago, IL, USA)을 이용하였다.

\section{결 과}

총 238 명의 환자가 본 연구에 포함되었으며 남자가 187 명, 여자가 51명이었고, 연령은 16 64세까지로 평균 37.2세였다. 환자의 추적 관찰 기간은 4 53개월로 평균 17.2 개월이었다. 추적 관찰 기간이 1 년 미만인 경우가 72 명(30.3\%), 1 년 이상 2년 미만 103명(43.3\%), 3년 미만 51명(21.4\%), 4년 미만 6명 (2.5\%), 그리고 4년 이상이 6명(2.5\%)이었다. ePTFE를 이용한 융비술과 휜 코 교정을 위한 절골술을 함께 시행한 경우는 87명(36.6\%)이었으며, 151명(63.4\%)은 절골술을 시행하지 않 았다. 이전에 외비 성형술을 받은 병력이 있는 재수술 환자는 10 명(4.2\%)이었으며 4명은 연골을 이용한 융비술을 시행받았 고, 3명은 실리콘을 사용하였으며 3명은 융비술을 시행받지 않았다. 연골을 이용하여 융비술을 시행받은 4명의 환자 중 3 명은 비중격 연골을 사용하였으며, 1 명은 이개 연골을 사용 하였다. 이전 성형 수술에서 ePTFE를 이용한 융비술을 시행 한 환자의 경우 재수술 이식물로 ePTFE를 사용하지 않아 본 연구에는 포함되지 않았다. ePTFE 1겹을 사용하여 $2 \mathrm{~mm}$ 융비술을 시행한 환자가 총 94명(39.5\%), 2겹(4 mm)을 사용 한 환자가 137명(57.6\%)이었으며, 7명(2.9\%)에서는 3겹(6 mm)
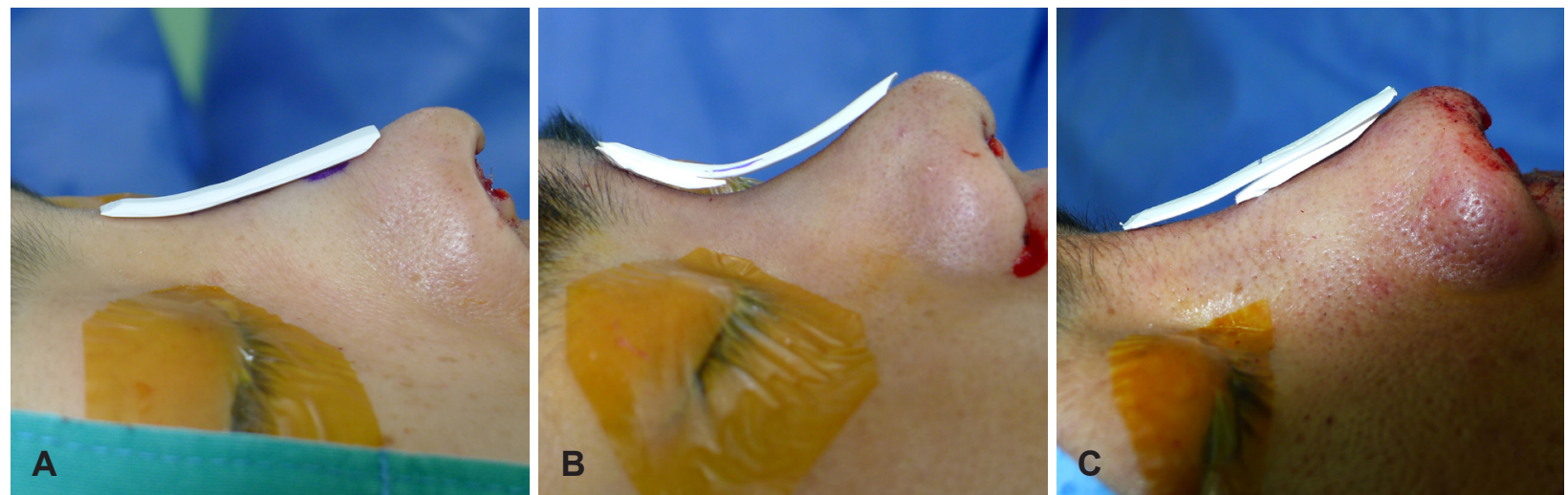

Fig. 2. The advantage of expanded polytetrafluoroethylene implants is that the thickness of implant can be freely adjusted to the shape of patient's face and dorsum. Single layer of $2 \mathrm{~mm}$ sheet was used to uniformly increase the height of the entire dorsum (A). To increase the nasion area, a double-layered implant was used on the part (B). $4 \mathrm{~mm}$ thickness implant was layered on supratip (C). 
을 사용하였다. 전체 환자 중 5명(2.1\%)에서 수술 후 추적 관 찰 중 이식물이 이동하였으며, 5 명 모두 수술 후 1 년 이내에 발생하였다. 5 명 모두 이동의 정도가 환자의 코 모양에 크게 영향을 줄 정도로 심하지 않아 재수술을 시행하지 않았다. 이 식물 이동으로 판단된 5 명의 환자 중 4 명은 수술 중 절골술 을 함께 시행한 환자군에 속하였으며 절골술을 함께 시행한 87 명의 환자 중 $4.6 \%$ 에 해당하였다. 반면 절골술을 함께 시 행하지 않은 151 명의 환자 중 1 명에서 이식물 이동이 있었으 며 $0.7 \%$ 에 해당하여 두 군 간 차이가 있었으나 통계적으로 유 의하지는 않았다 $(p=0.061)$. 수술 후 추적 관찰 중 $\mathrm{ePTFE}$ 임 플란트 두께의 감소에 의한 변형을 호소하는 환자는 없었고, 피부 발적, 부종 및 배농 등의 염증 소견은 단 한 명에서도 발 생하지 않았으며, 이식물이 노출된 경우도 없었다. 연구에 포 함된 환자에 대한 자세한 사항은 Table 1에 정리하였다.

\section{고 찰}

융비술은 동양인의 코 성형술에서 널리 시행되는 술식이 며, ${ }^{11)}$ 특히 비배부에 이식할 적절한 재료의 선택은 수술에서 가장 중요한 문제이다. 이식물로 사용되는 여러 인공 재료 중 실리콘은 낮은 가격과 사용의 편리성 때문에 가장 널리 사용 되고 있다. 그러나 연구자에 따라 5.5\%에 달하는 높은 수술 후 합병증을 보고하고 있으며, ${ }^{12)}$ 실리콘 특유의 수술 후 모습 때문에 거부감을 가지고 있는 의사와 환자들이 있다. ${ }^{3)}$

ePTFE는 1970년대부터 인체의 혈관 구조물을 대체하기 위 해 널리 사용된 재료로, ${ }^{13)}$ 1989년 Gore-tex(Gore, Flagstaff, $\mathrm{AZ}, \mathrm{USA}$ )를 처음으로 코 성형 재료로 사용한 이래, 높은 생 체 적합성, 낮은 조직 반응, 그리고 재료 자체의 안정성으로 인해 최근까지도 코 성형 재료로 널리 사용되고 있다. 그러나 융비술에 사용되어 온 Gore-tex는 코 성형 이식물로 개발되 어 승인된 재료가 아니며, 연조직 패치용으로 나온 제품을 코 성형에 사용하여 왔다(off-label). 따라서 재료의 구조가 치밀
하지 않아 이식 후 두께가 줄어드는 단점이 있었다. 2009년 본 연구진은 초음파를 이용한 ePTFE 두께 변화에 대한 연구 결과를 발표하였고, Gore-tex는 이식 후 추적 관찰 중 평균 $29 \%$ 정도 두께가 줄어들었다. ${ }^{6}$ 본 연구에 사용된 ePTFE는 코 성형 재료로 허가를 얻은 제품으로 기존의 재료보다 보다 치밀한 구조를 가지고 있으며 비배부에 이식된 후 두께가 줄 어들지 않는 것이 보고 되었다. ${ }^{79)} \mathrm{ePTFE}$ 는 특유의 공성 구조 로 인하여 세균의 감염에 취약하다고 알려져 있었지만 본 연 구에 사용된 재료의 경우 치밀한 구조로 인하여 조직 및 분 비물 등이 이식재로 침투하기 어려워 급성, 또는 지연성 염증 의 발생이 낮았을 것으로 판단된다.

2016년 Joo와 Jang ${ }^{14)}$ 은 융비술 이식재로 ePTFE를 사용 한 176명과 자가 늑연골을 사용한 68 명을 분석하여 수술 후 감염, 이식물 이동, 변형 등의 부작용을 비교하였고, 자가 늑 연골에서 오히려 부작용이 많았다고 보고하였다. 또한 2011년 Yap 등ㄱ은 ePTFE를 사용한 1054명의 융비술 결과를 발표하 였고, 수술 후 염증의 비율은 $0.38 \%$ 로 매우 낮았으며, 특히 1 차 수술인 경우 1008 예 중 단 1 예의 염증 $(0.10 \%)$ 만을 보고 하여 매우 안전한 재료임을 주장하였다. 이러한 연구 발표와 본 연구의 결과를 고려할 때 $\mathrm{ePTFE}$ 가 수술 후 감염, 염증 또 는 지연성 염증에 취약하다고 판단할 만한 근거는 부족하다. 특히 높은 감염율을 주장한 대부분의 논문은 위에서 언급한 것처럼 코 성형 재료로 개발되지 않은 Gore-tex를 사용한 수 술 결과에 대한 보고들이다.

본 저자들은 Gore사의 연조직 패치 재건용 ePTFE에 대 한 경험도 있으며 본 논문에 사용된 Surgiform과 비교하였을 때 전혀 다른 물리적 성질을 가지고 있었다. Surgiform 시트 는 Gore-tex보다 단단하기 때문에 비배부에 삽입 전 이식재 의 변연부를 부드럽게 제단해야 한다. 그렇지 않을 경우 피부 가 얇은 환자에서는 이식재의 경계가 만져지거나 외부에서 드 러나 보일 수 있다(Fig. 3).

융비술 후 발생하는 수술 후 감염이 수술에 사용된 이식재

Table 1. Demographics and surgical results

\begin{tabular}{|c|c|c|c|c|}
\hline & \multicolumn{3}{|c|}{ Patients, n (\%) } & \\
\hline & All $(n=238)$ & Osteotomy $(n=87)$ & No osteotomy $(n=151)$ & \\
\hline Male & $187(78.5)$ & 81 & 106 & \\
\hline Female & $51(21.5)$ & 6 & 45 & \\
\hline Prior rhinoplasty & $10(4.2)$ & 0 & 10 & \\
\hline \multicolumn{5}{|l|}{ Results } \\
\hline Migration & $5(2.1)$ & $4(4.6)$ & $1(0.7)$ & $p=0.061^{*}$ \\
\hline Infection & 0 & 0 & 0 & \\
\hline Inflammation & 0 & 0 & 0 & \\
\hline Implant exposure & 0 & 0 & 0 & \\
\hline
\end{tabular}




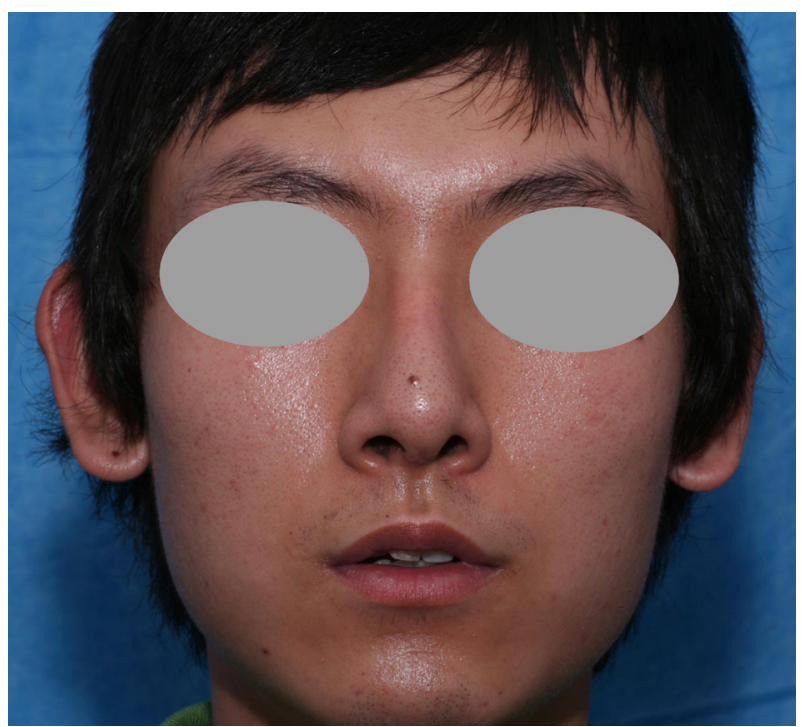

Fig. 3. An 8-month post-operative photograph of a 27-year-old man who underwent an augmentation rhinoplasty with expanded polytetrafluoroethylene and ostetomy. In this patient with thin skin, the marginal beveling of the implant was not performed. He complained that the upper marginal portion of the implant is palpated through the skin and the implant is visible. In addition, the implant migrated slightly to the right during the follow-up period.

와 관련이 있을 것이라는 많은 보고들이 있었다.15,16) 그러나 이식물 자체가 직접적으로 감염의 원인이 된다는 객관적 증거 는 아직 없으며, 각각의 이식재의 성질, 내구성 및 환자의 상 태를 고려하여 재료를 선택하는 것이 바람직하다. 저자들은 이전에 ePTFE를 사용한 재수술 환자에게는 다시 ePTFE를 사용하지 않았으며, 이전에 실리콘이나 연골을 사용하였다 고 하더라도 가능하면 인공 이식물을 사용하지 않으려고 하 였기 때문에 본 연구에 포함된 환자 중 재수술 증례는 10예 (4.2\%)뿐이었다.

수술 후 감염을 줄이기 위해 가장 중요한 것은 적절한 수술 전 준비 및 수술 시간의 단축이다. 수술 전 철저한 무균 원칙 에 따라 수술 부위를 소독하는 것이 필요하며, 수술을 준비 하는 전공의 또는 직원들에게 수술 준비를 할 수 있는 충분 한 시간을 주어야 한다. 또한 비강 내에는 다양한 상재균이 존재하며, 이러한 균주들이 이식물을 오염시킬 수 있기 때문 에 이식물 삽입 전후 각종 수술 기구들이 비배부와 비강 사 이에서 교차 사용되지 않도록 주의할 필요가 있다. 간과하기 쉬운 또 하나의 변수는 수술 시간이다. 수술 시간 또는 마취 시간이 길어질수록 수술 후 감염이 증가한다는 사실은 잘 알 려져 있다. ${ }^{17,18)}$ 따라서 외비 성형술, 특히 이식물을 사용할 때 에는 철저한 수술 전 준비와 함께 너무 오랜 시간 동안 수술 하지 않도록 조절 할 필요가 있다.

본 연구에 포함된 환자 중 $2.1 \%$ 에서 수술 후 이식물의 이 동이 있었으나 이는 이전에 발표된 연구 결과들과 비교하였을
때 크게 다르지 않은 수치이다. 절골술을 함께 시행한 군에 서 이식물 이동이 더 많았으나 통계적으로 유의하지는 않았 다. 휜 코 교정을 위한 절골을 시행한 경우 회복 과정에서 이 식물을 지지하고 있는 비골에 약간의 변형이 발생할 수 있고 이러한 변형이 이식물의 이동에 영향을 미쳤을 것으로 추정 할 수 있으며, 이러한 이식물의 이동은 모두 수술 후 1 년 이내 에 발생하였다. 연구 대상 환자가 더 늘어나면 통계적으로 유 의한 결과가 나올 것으로 생각한다. 따라서 절골과 융비술을 함께 시행한 환자에서는 수술 후 치료 과정 중 이식물의 이동 에 대해 보다 면밀하게 관찰할 필요가 있다. 다만 이식물의 이동하는 경우가 많지 않고, 미용적 문제를 유발할 정도는 아 니기 때문에 절골술을 시행한 환자에서 $\mathrm{ePTFE}$ 이식물의 사 용을 유보할 필요는 없다.

본 연구의 결과를 토대로 판단할 때, 융비술 재료로 개발되 어 승인받은 $\mathrm{ePTFE}$ 의 경우 철저한 수술 전 준비와, 적절한 무균 술식을 통해 사용할 경우 감염에 매우 안전한 재료로 판단된다.

\section{Acknowledgments}

None.

\section{ORCID}

Yong Gi Jung

$$
\text { https://orcid.org/0000-0001-7456-849X }
$$

\section{REFERENCES}

1) Shin MS. Present and future of aesthetic plastic surgery in Korea. J Korean Med Assoc 2011;54(6):581-8.

2) Gu Y, Yu W, Jin Y, Chen H, Ma G, Chang SJ, et al. Safety and efficacy of cosmetic augmentation of the nasal tip and nasal dorsum with expanded polytetrafluoroethylene: A randomized clinical trial. JAMA Facial Plast Surg 2018;20(4):277-83.

3) Yap EC, Abubakar SS, Olveda MB. Expanded polytetrafluoroethylene as dorsal augmentation material in rhinoplasty on Southeast Asian noses: Three-year experience. Arch Facial Plast Surg 2011;13(4): 234-8.

4) Wilson GC, Dias L, Faris C. A comparison of costal cartilage warping using oblique split vs concentric carving methods. JAMA Facial Plast Surg 2017;19(6):484-9.

5) Malone M, Pearlman S. Dorsal augmentation in rhinoplasty: A survey and review. Facial Plast Surg 2015;31(3):289-94.

6) Jung YG, Kim HY, Dhong HJ, Park KN, Lee HJ, Lim YJ, et al. Ultrasonographic monitoring of implant thickness after augmentation rhinoplasty with expanded polytetrafluoroethylene. Am J Rhinol Allergy 2009;23(1):105-10.

7) Jung YG, Kim KH, Dhong HJ. Ultrasonographic monitoring of new expanded polytetrafluoroethylene implant thickness after augmentation rhinoplasty. Am J Rhinol Allergy 2012;26(5):e137-41.

8) Peled ZM, Warren AG, Johnston P, Yaremchuk MJ. The use of alloplastic materials in rhinoplasty surgery: A meta-analysis. Plast Reconstr Surg 2008;121(3):85e-92e.

9) Kim JH, Lee JM, Ju HW, Lee JH, Jun AY, Park CH. Comparative study of morphological and histological changes between differently structured expanded polytetrafluoroethylene implants in an animal model. Am J Rhinol Allergy 2013;27(3):162-7. 
10) Shetty R, Paul MK, Barreto E, Sreekar H, Dawre S. Syringe-based wound irrigating device. Indian J Plast Surg 2012;45(3):590-1.

11) Kim HS, Park SS, Kim MH, Kim MS, Kim SK, Lee KC. Problems associated with alloplastic materials in rhinoplasty. Yonsei Med J 2014;55(6):1617-23.

12) Deva AK, Merten S, Chang L. Silicone in nasal augmentation rhinoplasty: A decade of clinical experience. Plast Reconstr Surg 1998;102(4):1230-7.

13) Florian A, Cohn LH, Dammin GJ, Collins JJ Jr. Small vessel replacement with gore-tex (expanded polytetrafluoroethylene). Arch Surg 1976;111(3):267-70.

14) Joo YH, Jang YJ. Comparison of the surgical outcomes of dorsal augmentation using expanded polytetrafluoroethylene or autologous costal cartilage. JAMA Facial Plast Surg 2016;18(5):327-32.

15) Genther DJ, Papel ID. Surgical nasal implants: Indications and risks. Facial Plast Surg 2016;32(5):488-99.

16) Jang YJ, Moon BJ. State of the art in augmentation rhinoplasty: Implant or graft? Curr Opin Otolaryngol Head Neck Surg 2012; 20(4):280-6.

17) Puffer RC, Murphy M, Maloney P, Kor D, Nassr A, Freedman B, et al. Increased total anesthetic time leads to higher rates of surgical site infections in spinal fusions. Spine 2017;42(11):E687-90.

18) Cheng H, Chen BP, Soleas IM, Ferko NC, Cameron CG, Hinoul P. Prolonged operative duration increases risk of surgical site infections: A systematic review. Surg Infect (Larchmt) 2017;18(6):722-35. 